\title{
Aesthetic practitioner as a physician and businessperson - Is it achievable?
}

\section{Elena Thomaidou}

\author{
Department of Dermatology, Hadassah- Hebrew University Medical Center, Jerusalem, Israel
}

Corresponding author: Dr. Elena Thomaidou, E-mail: dr.elenathomaidou@gmail.com

\begin{abstract}
Aesthetic medicine subspecialty is no longer limited to the fields of plastic surgery and dermatology, as many specialties are offering aesthetic medical procedures to better accommodate their patients' aesthetic needs. During the last decade there is an enormous increase of cosmetic treatments worldwide and the absence of regulations in aesthetic practice has become more noticeable. This article illustrates the challenges that every aesthetic physician must overcome daily to maintain high ethos and make decisions according to patient's best interest and safety. Aesthetic practitioner should be more than a businessperson with a medical degree. If they place their integrity and moral standards to the test, then they will continue to be judged by their colleagues and society. Is it possible to maintain the same moral obligations during cosmetic procedures as with any other medical treatments?
\end{abstract}

Key words: Aesthetic dermatology; Cosmetic dermatology; Ethics; Malpractice; Safe practice; Good clinical practice

\section{INTRODUCTION}

"A physician shall be dedicated to provide competent medical service in full professional and moral independence, with compassion and respect for human dignity" as it has been described by Word Medical Association International Code of Medical Ethics [1]. This article will explain the challenges that every aesthetic physician must overcome daily to maintain high ethos and make decisions according to patient's best interest and safety. Aesthetic medicine subspecialty is no longer limited to the fields of plastic surgery and dermatology, as many specialties are offering aesthetic medical procedures to better accommodate their patients' aesthetic needs [2]. How difficult is for all the aesthetic practitioners to set their priorities straight? People are willing to spend a lot of money for staying forever young having the perfect facial skin and body. Therefore, in the western world, financial incentives for the aesthetic practitioners can be dangerous against ethical practices [3].

In UK, cosmetic interventions are booming business, which worth of $£ 2.3$ billion in 2010 , and it was estimated to rise to $£ 3.6$ billion by 2015 as it was reported by Professor Sir Bruce Keogh KBE [4]. On the other side of the Atlantic Ocean, American society for aesthetic plastic surgery reported more than $\$ 13.5$ billion spent for the first time ever in the year of 2015, with surgical procedures accounted for $58 \%$ of the total expenditures, and nonsurgical procedures accounted for 42\% [5]. A comprehensive analysis, which was published in USA in August 2016, indicated that the current medical aesthetic market was worth $\$ 52,405$ million for both service and product revenue, which over the next five years was expected to grow at 5.5\% Compound annual growth rate (CAGR) and to hit \$69,786 million in 2021 . The invasive aesthetic procedures were set to grow at a CAGR of $4.3 \%$, while the non-invasive ones were supposed to reach a CAGR of $4.5 \%$ over the coming five-year period [6]. Therefore, due to this increase of cosmetic treatments worldwide, the absence of regulations in aesthetic practice has become more noticeable. In fact, in the review document regarding the regulation of cosmetic interventions in U.K., the committee was surprised to discover that non-surgical interventions, which can have major and irreversible

How to cite this article: Thomaidou E. Aesthetic practitioner as a physician and businessperson - Is it achievable?. Our Dermatol Online. 2018;9(2):210-214.

Submission: 24.09.2017; Acceptance: 18.11.2017

DOI: 10.7241/ourd.20182.28 
adverse impacts on health and well-being, are almost entirely unregulated [4].

\section{THE ROLE OF AESTHETIC PRACTITIONER AS A PHYSICIAN}

Physicians, who choose to work in aesthetic areas, should maintain a high standard of safety. Patients are more demanding and treatments are embellishments, so there is little tolerance for poor results and complications are less acceptable [7]. Prendergast mentioned in his book that there is no "medical" indication for the procedure and the physician is only responsible for proposing a method by which the patient's goal should be achieved [1]. Patients must be able to trust that their physicians are always acting in the patients' best interests [7]. The Council of Medical Speciality in U.K. states that "physicians should treat each patient with honesty, compassion, dignity, respect for individual autonomy and educate them about health issues" [8].

The role of physician demands on their cautious judgment guide about the different aesthetic treatments that can be provided to patients, rather than simply yielding to patients' demands [7]. Unfortunately, the patient's conception depends to media advertising resulting to exaggeration of patient's expectations on aesthetic results of procedures. Therefore, legal claims are higher than other surgical operations, especially if physicians do not respect patient's autonomy by not explaining treatment process and outcomes [9]. The initial consultation must not serve the purpose of "selling" an aesthetic procedure, but placing the interests of patients above those of the physician is one of the fundamental principles of professionalism $[1,10]$.

The principle of informed consent tends to reflect the concept of autonomy of the person requiring and requesting medical and/or surgical interventions [11]. Seven criteria relate to an informed consent: (i) competence to understand and to decide, (ii) voluntary decision making, (iii) disclosure of material information, (iv) recommendation of a plan, (v) comprehension of terms and (vi) decision in favour of a plan, and (vii) authorization of the plan [9]. A person, who is a candidate for an aesthetic procedure, must complete all the criteria in order to give an informed consent, and every aesthetic physician must make sure patients are given enough time and information before they decide whether to have an intervention [12]. If the patients ask for a cosmetic treatment that the physician considers unnecessary and/or dangerous, then it is physician's obligation to discuss the issues and explore the reasons for their request [13]. Always, it is important during the first consultation to consider the patients' psychological needs and if necessary to seek expert advice from colleagues prior to any intervention [12]. It is extremely challenge for every aesthetic practitioner to go ahead with an unnecessary treatment since the financial incentives outweigh his/her decision.

Aesthetic practitioners should be open and honest about their skills, experience, fees and conflicts of interests [12]. Attendance only at a training course is insufficient to become competent in a procedure, whether this is a surgical or a non-surgical procedure. As it is mentioned in the Professional standards for cosmetic practice, direct practice is also necessary. Therefore, it is highly recommended that all practitioners undertake a period of formal or informal mentorship and they must keep their skills up to date by undertaking relevant continuing professional development [13].

\section{THE ROLE OF AESTHETIC PRACTITIONER AS A BUSINESSPERSON}

A businessperson's main objective is to maximize profit by increasing productivity and minimizing costs, but an aesthetic practitioner must not follow this goal, as this would have negative implication on the quality of the service offer $[14,15]$. The role of the dermatologist, for example, is transforming from a traditional healer into one of a businessperson, who will promote "big ideas". "Bluffing, puffing, and spinning", which were described by Illingworth [16], are acceptable marketing practices for businesses but are those behaviours acceptable for physicians as well?

In microeconomics, the profit maximization rule states that if a company chooses to maximize its profits, it must choose that level of output where marginal cost (MC) is equal to marginal revenue (MR) [14]. In more simple terms, profit maximization is an advantage for a company, but it can be a disadvantage for consumers if the company starts to use cheaper products/services or decides to raise prices especially when the firm has a monopoly power in the market [17]. If this concept is applied in the health care sector then the outcome can be dangerous and unethical for the patients. According 
to Sidorsky, it may be argued, that healthcare providers should not function merely as profit-maximizing entities since they principally promote patient health [7]. Unfortunately, in the free market economy due to the minimum government interference through insufficient laws and regulations, this might not always be achievable.

Firstly, most aesthetic practitioners want to maximize their profit by increasing provision of services in their clinics. Recently, this has been achieved by hiring an aesthetician to perform a variety of skin-care procedures like mild chemical peels, microdermabrasion etc. However, it is important to remember that aestheticians treat "clients," not "patients" [18]. In the USA, there are many aesthetic practices, where "dermatology physician assistant (PA)" assists during the cosmetic procedure and "physician extenders" (PE) are employed for basic dermatological evaluation and treatments [19]. Therefore, as correctly stated by Slade and Grant-Kels [18], it would be appropriate only if the aesthetician, PA or PE are employed in a cosmetic practice to receive only patients, who are first evaluated by a physician and are referred to them for specific treatment part of the medical plan of care. In addition, they recommended that aesthetic practitioners need to monitor the scope of practice, delegate appropriately, and manage patient expectations [18]. Secondly, aesthetic practitioners in order to maximize their profit they might try to minimize their costs by cheaper unauthorized products for their treatments.

Recently, aesthetic physicians have achieved profit maximization by allying with some major cosmetic companies [15]. However, as it was mentioned in the editorial note of Kassirer and Angell [3] "it is one thing to recommend health-related products based on careful scientific scrutiny; it is another to enter into an exclusive marketing arrangement with a single company in which royalties are linked to sales". In addition, some physicians become a paid spokesperson at scientific and professional meetings, for off-label cosmetic products or aesthetic uses of products and procedures, without any mention of the risks or actual approved indications in order to promote them [15]. Are these ethical behaviours? The statement of American Academy of Dermatology's on office dispensing, for example, emphasises that "Dermatologists should not dispense or supply drugs, remedies or appliances unless it is manifestly in the best interest of their patients" [7]. Often dermatologists do not only sell cosmetic products in their practices, but in order to maximize their profits they have produced their own skincare products, sometimes devoid of evidence based support. Cantor mentioned in her article that every product should be evaluated by randomized, double-blinded and placebo controlled trials regardless the overall cost burden for the physicians [20].

Furthermore, information asymmetry, one type of market failure in the free market, is a challenging issue in aesthetic practice. According to definition, asymmetric information is a situation in which one party in a transaction has more or superior information compared to another [21]. In aesthetic practice, this often happens when the doctor knows more than the patient. Potentially, this could be a risky situation because one party can take advantage of the other party's lack of knowledge [21]. Information must be communicated clearly and respectfully to the patient and a shared understanding of expectations and limitations that consent to intervention is sought by the doctor [12]. However, few practitioners' desire to make profit might carry on unnecessary treatments hiding important information.

Aesthetic physicians, who want to be good businesspersons, need to apply a business plan consisting of their financial, marketing, and operational strategies and actions of their practice. It is a demanding, timeconsuming process to apply a business plan as it requires setting accountable, realistic and measurable objectives that should be achieved in the future. These would be even more difficult for a practitioner of no business background. The purpose of advertising is to increase the demand of services and products and building brand loyalties to make their demand more inelastic. This would allow practitioners to charge higher prices for their services without considerable fault in their quantity demanded raising their total revenues and enhance their profits [22]. However, spending on advertising is highly expensive to carry out and in many cases, it might be misleading to the consumers due to false claims regarding the advertising product or service. If aesthetic practitioners, for example, market their services irresponsibly by making unjustifiable claims about interventions, trivialising the risks involved, or using promotional tactics might encourage people to make "ill-considered" decisions [12]. Ethical dilemmas related to the commercialization of medicine have been a challenging matter in the western world [23]. White -coat endorsement is a marketing tool that has been used in aesthetic medicine for promotion cosmetic products as Cantor said "Great products need no MD endorsement, the market will find them" [20]. 


\section{DISCUSSION}

Aesthetic medicine makes profit from the ideology of a society that serves only vanity, youthfulness and personal success, and one which is losing sight of the real values [24]. In fact, "a person having a nonsurgical cosmetic intervention has no more protection and redress than someone buying a ballpoint pen or a toothbrush", as it was mentioned by Professor Sir Bruce Keogh KBE [4]. The tricky question is "How do we approach this issue?" Actions should be taken for enhancing patients' safety. The first step in every solution and decision-making process is to identify and define the problem [25]. In this situation, a worldwide concern must be confronted.

An informed and empowered public is crucial to driving up the standards of aesthetic practice and the quality of care provided [14]. Today, it is believed that the public is more informed through social media and advertisements, but they are not better or correctly informed. Therefore, aesthetic practitioners have an obligation to educate their patients using up to date evidence that will favour patient's best interest reducing asymmetry information.

In addition, a certification system should be introduced or a governmental body should be assigned to monitor the quality and safety of products that are used by the practitioners [12]. Dermal fillers, for example, are used by healthcare and non-healthcare practitioners with no requirement for previous experience, training or even basic knowledge of the product. For example, the scope of the EU Medical Devices Directive, in the European Union, should be extended to include all cosmetic implants including dermal fillers, and legislation should be introduced to classify fillers as a prescription-only medical device [12]. All practitioners must be registered and the register should be independent of professional groups or commercial bodies. Entry to the register, for example, should be subject to: (i) achievement of accredited qualification; (ii) premises meeting certain requirements; (iii) adherence to a code of practice that covers handling complaints and redress, insurance requirements, responsible advertising practice and consent practices; and (iii) continued demonstration of competence through an annual appraisal [26].

The initial question of this article was whether an aesthetic practitioner can be a physician and a businessperson at the same time. Both of their roles are discussed above, but my own opinion regarding the subject would be supported by the following example. The scope of dermatologic practice is broadening owing to recent advances in cosmetic services; these services reduce the dermatologic workforce resources that can be devoted to medical dermatologic patients [27]. It is not illegal or unethical when aesthetic practitioners, like dermatologists, decide to restrict their everyday practice to only cosmetic or procedural dermatology [19]. However, what will it happen if most dermatologists have no available time to treat complex dermatological conditions or follow up suspicion malignant skin lesions? Tsang and Resneck [28] stated in their article that even for patients willing to pay for face dermatology appointment due to changing pigmented lesions, the mean wait-time was 38 days (median, 26 days) in the metropolitan areas in the United States. However, Meffert and Villegas mentioned that the waiting time for a botulinum toxin injection appointment also varied widely with geographic location (6-32.5 days) but had a relatively short median wait of 8 days [19]. Therefore, this argument raised an important issue that there is an increase shift from classical medical dermatology to the more cash-driven cosmetic procedure and sometimes due to shortage of dermatologists in certain areas several dermatological conditions remain underdiagnosed

In conclusion, I agree with the statement first mentioned by Cantor in one of her articles "Ethics requires doctors to be more than just salespeople with an M.D" [20] I strongly believe that aesthetic practitioners, especially physicians, must set their priorities straight. If they decide to practice aesthetic medicine, they need to appreciate that they have the same moral obligations to the cosmetic patients as with any other patients. Cosmetic dermatologist should follow the good medical practice guidance as General Medical Council in U.K. states: 'Good doctors make the care of their patients their first concern: (i) they are competent, keep their knowledge and skills up to date, establish and maintain good relationships with patients and colleagues, they are honest and trustworthy, and act with integrity and within the law' [29]. If they continue to place their integrity and moral standards to the test, they will continue to be judged by their colleagues, society [30].

Finally, every aesthetic practitioner should remember that pull of profit cannot be a primary motivation like in the case of businessperson. Instead, they should remember what Sir William Osler advised the 'Students of Medicine' : "Seek your own interests, make of a high 
and sacred calling a sordid business, regard your fellow creatures as so many tools of trade, and, if your heart's desire is for riches, they may be yours; but you will have bartered away the birthright of a noble heritage, traduced the physician's well deserved title of the Friend of Man, and falsified the best traditions of an ancient and honourable Guild" [21,30,31].

\section{REFERENCES}

1. Prendergast PM: Aesthetic medicine: art and techniques. Berlin, Heidelberg, Springer Berlin Heidelberg Imprint: Springer 2012.

2. A4mcom: The American Academy of anti-aging Medicine, A4mcom. (2016) Available from: URL: http://www.a4m.com/ fellowship-aesthetic-overview-what-is-aesthetic-medicine.html (Accessed: 18 April 2017)

3. Kassirer JP, Angell M.The High Price of Product Endorsement. N Engl J Med. 1997;337:700.

4. Great Britain, Department of Health. Regulation of cosmetic interventions: government response, Department of Health 2014.

5. Surgeryorg: The American Society for Aesthetic Plastic Surgery, Surgeryorg. Available from: URL: https://www.surgery.org/ media/news-releases/american-society-for-aesthetic-plasticsurgery-reports-more-than-135-billion-spent-for-the-first-time-ever (Accessed at: 8 April, 2017)

6. Reportsnreports: Medical Aesthetics Market Worth $\$ 69,786$ Million by 2021. 2017. Available from: URL: http://www.prnewswire.com/ news-releases/medical-aesthetics-market-worth-69786-millionby-2021-589681961.html (Accessed at: 2 May 2017).

7. Bercovitch L, Perlis C. The Price Is Right: Office Dispensing and Product Pricing. Dermatoethics. Springer London Dordrecht Heidelberg New York, Chapter 23 2012a

8. Charles SC, Lazarus JA, Workgroup on the Ethic of Medicine Council of Medical Specialty Societies. For a list of workgroup leaders and members and their specialty society affiliations, please see the web site at http://www.ewjm.com. Reframing the professional ethic: The Council of Medical Specialty Societies consensus statement on the ethic of medicine. West J Med. 2000;173:198-201.

9. Nejadsarvari N, Ebrahimi A. Different Aspects of Informed Consent in Aesthetic Surgeries. World J Plast Surg. 2014;3:81-6.

10. ABIM Foundation. American Board of Internal Medicine, ACPASIM Foundation. American College of Physicians- American Society of Internal Medicine, European Federation of Internal Medicine (2002). Medical professionalism in the new millennium: a physician charter. Ann of Intern Med. 2002;136:243-6.

11. Mallardi V. [The origin of informed consent]. Acta Otorhinolaryngol Ital. 2005;25:312-27.

12. General Medical Council. Guidance for all doctors who offer cosmetic interventions: a public consultation on our draft guidance 2015.

13. Rcsengacuk: Royal College of Surgeons, Rcsengacuk. 2016. Available from: URL:https://www.rcseng.ac.uk/surgeons/surgical- standards/working-practices/cosmetic-surgery/documents/csicconsultation-document-2015. (Accessed at: 15 April 2017)

14. Intelligenteconomistcom: Intelligent Economist. 2016. Available from: URL: https://www.intelligenteconomist.com/profitmaximization-rule/( Accessed at: 12 April 2017).

15. Newburger AE, Caplan AL. Taking ethics seriously in cosmetic dermatology. Ach Dermatol. 2006;142:1641-2.

16. Illingworth P. Bluffing, puffing and spinning in managed-care organizations. J Med Philosophy. 2000;25:62-76.

17. Investorwordscom: Investor Words com. 2016 Available from: URL: http://www.investorwords.com/7690/profit_maximization. html (Accessed at: 12 April 2017).

18. Slade K, Grant-Kels JM. Employing an aesthetician in a dermatology practice: Facts and controversies. Clin Dermatol. 2013;31:777-9.

19. Bercovitch L, Perlis C. 'Boutiques, Botox ${ }^{\circledR}$, and Basal Cells: Can Dermatology Set Its Priorities? ' Dermatoethics. Springer London Dordrecht Heidelberg New York, Chapter 22 2012b.

20. Bercovitch L, Perlis C.' My Elixir, MD: Morphing a Medical Degree into a Skincare Brand.' Dermatoethics. Springer London Dordrecht Heidelberg New York, Chapter 24 2012c.

21. Root: Investopedia. 2003 Available from: URL: http://www. investopedia.com/terms/a/asymmetricinformation.asp. (Accessed at: 9 April 2017).

22. Anderson A. Economics $5^{\text {th }}$ edn. Essex: Pearson Education 2008.

23. Bercovitch L, Perlis C. Marketing the Physician:From Antitrust to Distrust.' Dermatoethics. Springer London Dordrecht Heidelberg New York, Chapter 25, 2012d.

24. Mousavi, S. The Ethics of Aesthetic Surgery. J Cuts Aesth Surg. 2010;3:38-40.

25. Porter EM., Thomas HL.The Strategy That Will Fix Health Care. [ONLINE] 2017 Available from: URL: https://hbr.org/2013/10/ the-strategy-that-will-fix-health-care. [Accessed 2 August 2017].

26. Bcdginfo: British Cosmetic Dermatology Group, Bcdginfo. 2016. Available from: URL: http://www.bcdg.info /about/ cosmeticdermatology-page-2 (Accessed at: 22 April 2017).

27. Suneja T, Smith ED, Chen G, Zipperstein, KJ, Fleischer AB. Feldman, SR. Waiting times to see a dermatologist are perceived as too long by dermatologists: Implications for the dermatology workforce. Arch Dermatol. 2001;137:1303-7.

28. Tsang MW, Resneck JS. Even patients with changing moles face long dermatology appointment wait-times: A study of simulated patient calls to dermatologists. J Amer Acad Derm. 2006;55:54-8.

29. Gmc-ukorg. General Medical Council, Gmc-ukorg. 2016. Available from: URL:http://www.gmc-uk.org/Tomorrow_s_Doctors_1214. pdf_48905759.pdf, (Accessed at: 22 April, 2017).

30. Imadojemu, S, Fiester, A Reply to letter to the editor: "Are there moral obligations to cosmetic dermatology patients beyond informed consent?". J Amer Acad Derm. 2013;69:817-8.

31. Golden RC. Aequanimitas. J R Soc Med. 1995;88:302.

Copyright by Elena Thomaidou. This is an open-access article distributed under the terms of the Creative Commons Attribution License, which permits unrestricted use, distribution, and reproduction in any medium, provided the original author and source are credited.

Source of Support: Nil, Conflict of Interest: None declared. 